\title{
PENERAPAN DECISION TREE DALAM AGEN CERDAS "UNDA ANAK PINTAR" PERMAINAN EDUKASI MUATAN LOKAL BAHASA BANJAR
}

\author{
Asep Nurhuda ${ }^{1}$, Reza Andrea ${ }^{2}$ \\ STMIK Widya Cipta Dharma ${ }^{1,2}$ \\ Jl. M. Yamin No. 25, Samarinda, 75123 \\ Sur-el : nurhuda@wicida.ac.id ${ }^{1}$, reza@wicida.ac.id ${ }^{2}$
}

\begin{abstract}
The educational game "Unda Anak Pintar" is research and development of a puzzle game, it was designed to sharpen memories. In this game, players must read random letters and make words in the Banjar language. Artificial intelligence is also applied in this research. Using the decision tree, game agents can accompany children to play like teachers. The game agent as a virtual teacher can provide sad and happiness emoticon according to the game environment. The results of this study, AI make educational games more interesting and interactive for children.
\end{abstract}

Keywords: Banjar, puzzle, educational game, decision tree

\begin{abstract}
Abstrak : Penelitian berjudul game edukasi "Unda Anak Pintar" adalah penelitian pengembangan jenis permainan puzzle yang dirancang untuk mengasah ingatan dalam bentuk susunan kata. Dalam permainan ini pemain harus mengatur huruf secara acak dan membuat kata dalam bahasa Banjar. Teknologi kecerdasan buatan juga diterapkan pada penelitian ini. Menggunakan model decision tree yang diterapkan pada agen cerdas membuat karakter cerdas dapat menemani anak bermain seperti guru. Agen permainan dalam bentuk guru dapat memberikan ekspresi sedih dan bahagia sesuai dari lingkungan permainan. Hasil penelitian ini menjadikan permainan edukasi lebih menarik dan interaktif bagi anak-anak.
\end{abstract}

Kata kunci: Banjar, puzzle, permainan edukasi, pohon keputusan

\section{PENDAHULUAN}

Muatan lokal adalah materi pelajaran dan pengenalan suatu budaya untuk anak sekolah, tidak hanya terdiri dari keterampilan, kerajinan tangan, tetapi juga menjaga manifestasi budaya dari konten dan kebiasaan lokal [1,2]. Mempelajari muatan lokal bahasa Banjar dimaksudkan untuk menjaga kelestarian budaya Banjar, juga memiliki identitas dan kepribadian wilayah selain kepribadian nasional [3]. Dengan demikian pelestarian bahasa dan budaya tidak hilang seiring dengan perkembangan zaman. Bahasa Banjar adalah bahasa suku Banjar di
Kalimantan Selatan (Kalimantan, Indonesia) $[4,5]$.

Anak Pintar" sebagai muatan lokal pengembangan bahasa Banjar dan agen cerdas (game agent) dengan model decision tree. kata "Unda" dalam bahasa Banjar berarti "saya (anak muda)", jadi judul "Unda anak cerdas" berarti aku anak pintar. Diharapkan permainan ini menjadi aplikasi hiburan dan pembelajaran yang menarik dan bertujuan untuk mengenalkan budaya dan bahasa Banjar. Logika pohon keputusan yang diterapkan ke dalam agen cerdas akan memberikan aksi-reaksi, mengamati, dan bertindak pada suatu kondisi sehingga terlihat 
seperti teman bermain yang nyata, dalam decision tree atau di dalam permainan dinamakan game tree dikenal sebagai teknik untuk pemodelan fenomena atau kondisi berbasis event. Pohon keputusan inilah yang akan membuat karakter game yang mendampingi anak bermain dapat berpikir sendiri sesuai keadaan kondisi permainannya. [6,7] Game tree berbentuk pohon dengan simpul menunjukkan posisi dalam permainan dan sisi menunjukkan langkah-langkah yang diambil, dimana logika ini menggunakan alur seperti ranting pohon [8-10]. Agen permainan dibuat dalam bentuk karakter animasi yang dapat diekspresikan dari setiap langkah pemain. Jika gerakan pemain salah, maka agen cerdas akan terlihat kecewa dan sebaliknya. Identifikasi masalah yang ada dalam penelitian ini adalah, tidak ada penelitian tentang bagaimana membangun model pohon keputusan dalam game berjenis puzzle yang memperkenalkan pembelajaran muatan lokal tentang bahasa Banjar. Belum adanya agen cerdas yang diciptakan dengan tujuan berperan sebagai guru [11-13] yang menemani anak bermain.

Tujuan dari penelitian ini adalah, mengembangkan permainan edukasi menyusun huruf (puzzle) dalam belajar bahasa Banjar, menerapkan logika pohon keputusan yang dalam bentuk kerangka pemikiran untuk diterapkan dalam gane agent. Menguji cobakan pengujian beta kepada siswa dan guru Sekolah Dasar (SD) hingga aplikasi siap didistribusikan.

\section{METODOLOGI PENELITIAN}

Penelitian akan dilakukan melalui beberapa tahap pengembangan multimedia sebagai berikut $[6,9,14-16]$

1) Studi literatur tentang proses pembuatan game edukasi dan penerapan algoritma yang digunakan, dan pengumpulan bahan (material collecting)

2) Proses pengembangan edugame dengan metode pengembangan sistem multimedia, dari tahap desain hingga tahap perakitan pohon keputusan ke dalam sistem decision tree.

3) Memasang aplikasi edugame ke smartphone anak-anak dan guru SD.

4) Melakukan pengujian beta dalam bentuk kuesioner kepada anak-anak dan guru SD dan meninjau dokumen.

5) Menganalisis hasil kuesioner dan review penerapan algoritma pohon keputusan di edugame.

6) Distribusi dan analisis ulang hingga hasil pengujian menghasilkan nilai persentase yang memuaskan.

Setiap langkah dilakukan secara berurutan dari langkah pertama hingga langkah terakhir, setiap langkah yang telah dilakukan harus ditinjau, terdaftar dalam kerangka penelitian sebagai berikut (lihat gambar 1).

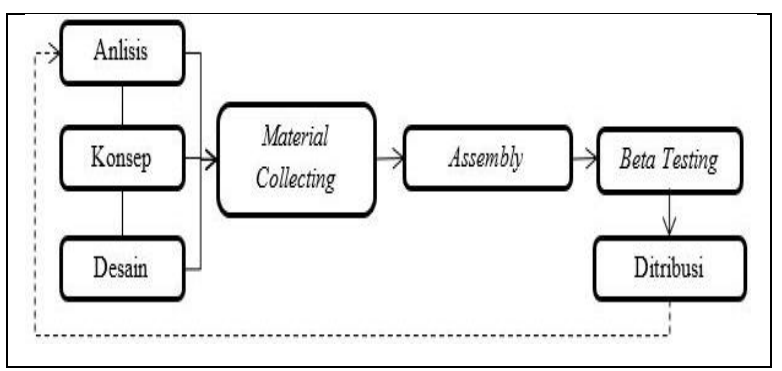

Gambar 1. Kerangka Penelitian 
Desain pohon keputusan didasarkan pada peristiwa yang terjadi dalam log aktivitas anak saat bermain. Waktu dan jumlah puzzle gambar disesuaikan dengan kerangka prioritas perilaku agen cerdas. Karakter dirancang dengan kerangka kerja yang berbeda untuk setiap menu pembelajaran dan permainan, ini dilakukan agar agen dapat bertindak sebagai pendamping terbaik. Di bawah ini dalam gambar 2 adalah desain pohon keputusan yang akan diterapkan pada agen cerdas.

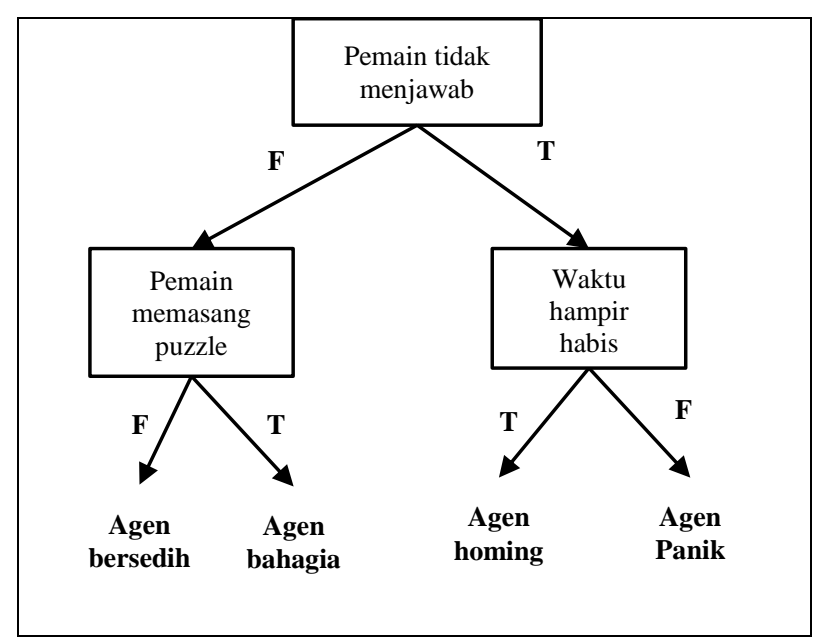

Gambar 2. Model Game Tree

Model gambar 2 menjelaskan bahwa pada awal permainan, karakter (agen) yang menjadi teman siswa bermain dalam keadaan idle (homing). Karakter akan bergerak sebagai respons terhadap gaya bermain anak saat mencocokkan huruf teka-teki. Pada saat puzzle huruf cocok, maka karakter akan memberikan respons yang bahagia, sebaliknya bila tidak cocok, maka karakter tersebut akan memberikan respons yang sedih dan tetap memberikan semangat untuk menemukan huruf lain. Kondisi terakhir adalah ketika waktu habis, agen cerdas akan memberikan respons panik dan memberikan pengingat bahwa waktu hampir habis

\section{HASIL DAN PEMBAHASAN}

Permainan edukasi "Unda Anak Pintar" muatan lokal bahasa Banjar adalah permainan edukatif yang terdiri dari kategori permainan puzzle yang dapat mengajak pemain untuk bermain sambil belajar dengan santai, mudah dipelajari atau dimainkan oleh anak. Konsep permainan ini memiliki aturan sederhana dan menampilkan konten yang dirancang untuk para penggunanya untuk semua umur, terutama anakanak. Game ini memiliki empat opsi menu dalam adegan pembukaan belajar, bermain, dan juga menu keluar,

Edugame ini memiliki aturan main bahwa pemain harus mencocokkan huruf dan meletakkannya di kotak kosong sesuai dengan gambar materi atau kata dan diubah menjadi ejaan dalam bahasa Banjar, ada waktu di setiap babak game yang bisa melatih kecepatan dalam mengingat kata-kata bahasa Banjar dan ada juga skor di setiap babak yang telah dimainkan. Konsep ini rancang untuk antarmuka pada gambar 3. Aplikasi ini dibangun dalam 2 bahasa, ada dalam Bahasa Inggris dan Bahasa Indonesia. Pemain dapat memilihnya di scene pembuka. Dalam adegan ini, pemain dapat membagikan game ini ke media sosial Facebook dan Twitter, dan pemain dapat menekan tombol pengaturan untuk mengatur volume sound $f x$ dan musik. 


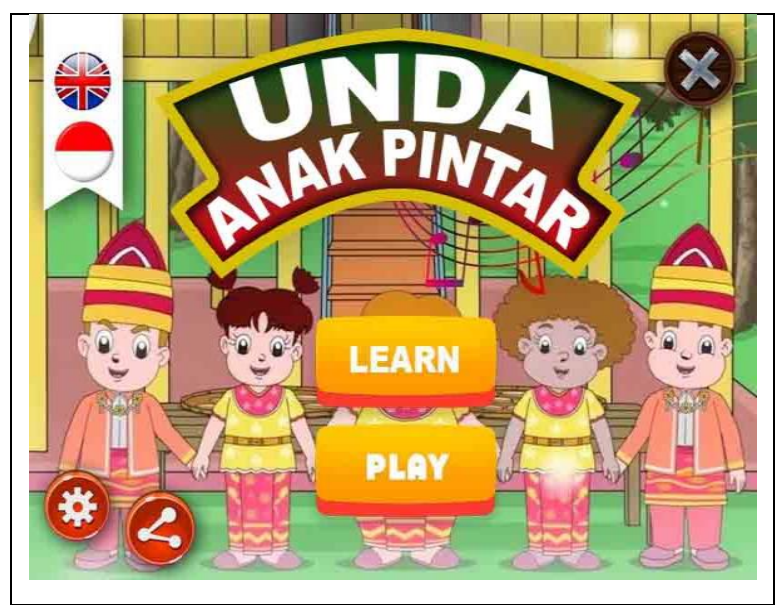

Gambar 3. Scene Pembukaan

Dalam menu belajar (gambar 4), pemain akan belajar tentang kata-kata dalam basis bahasa Banjar yang dibuat dalam tabel yang mirip dengan kamus bahasa. Pemain dapat mempelajari 100 kata Banjar di aplikasi ini. pemain dapat menerjemahkan bahasa Banjar ke bahasa Inggris dan Bahasa Indonesia, dan sebaliknya. Pemain dapat mencari kata-kata Banjar, Inggris, dan Indonesia dengan menekan tombol cari.

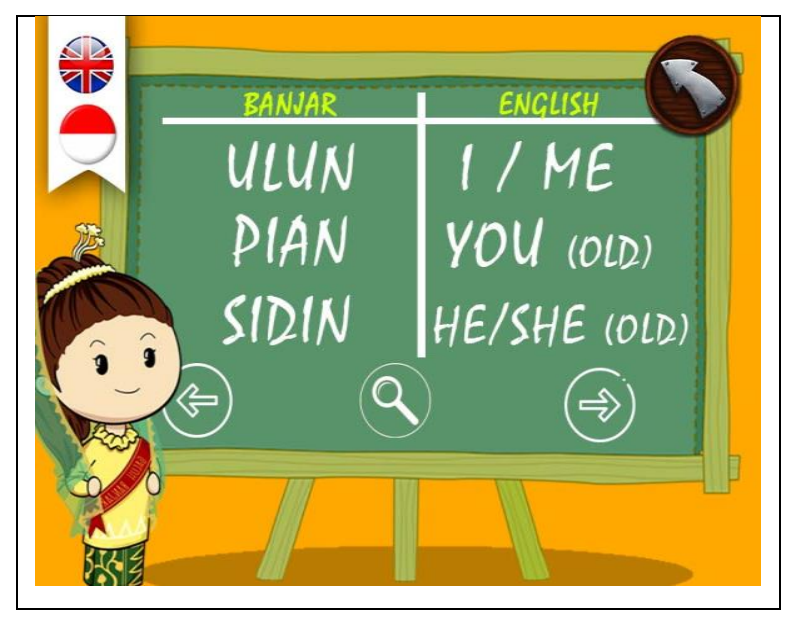

Gambar 4. Scene Belajar

Untuk memulai permainan, pemain harus menekan tombol play. Dalam permainan, pemain akan diberikan waktu 30 detik untuk mencocokan objek gambar yang terdiri dari beberapa kotak puzzle huruf (lihat gambar 5).
Jika pemain kehabisan waktu sebelum menyelesaikan permainan, maka permainan akan game over, dan pemain dapat memilih untuk mengulang atau kembali ke menu utama dengan menekan tombol pengaturan. Setiap babak juga tersedia dalam 2 versi bahasa, ada bahasa Inggris dan bahasa Indonesia.

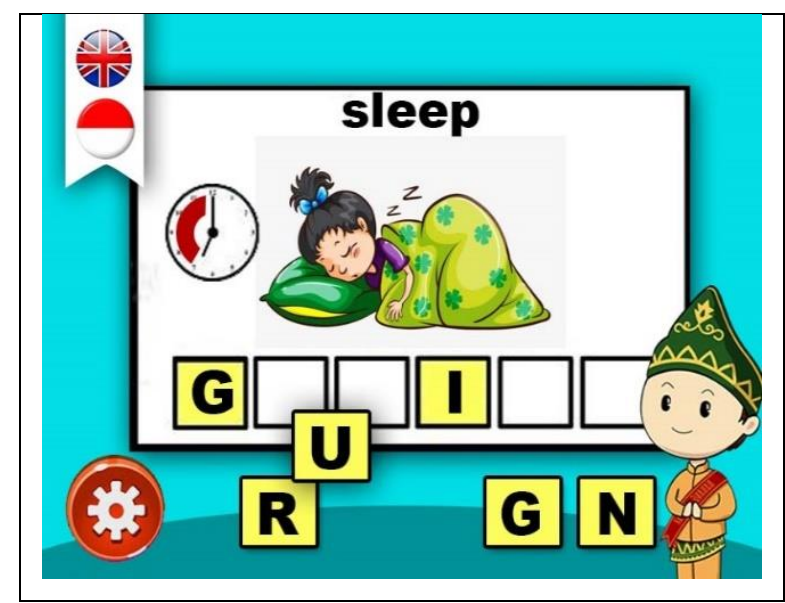

Gambar 5. Gameplay

Model pohon keputusan (gambar 6) diterapkan sebagai pola ekspresi karakter lucu pada permainan, karakter lucu akan memberikan pemberitahuan dan berbicara jika pemain salah atau cocok dengan puzzle, dan memberikan pemberitahuan ketika waktu habis.

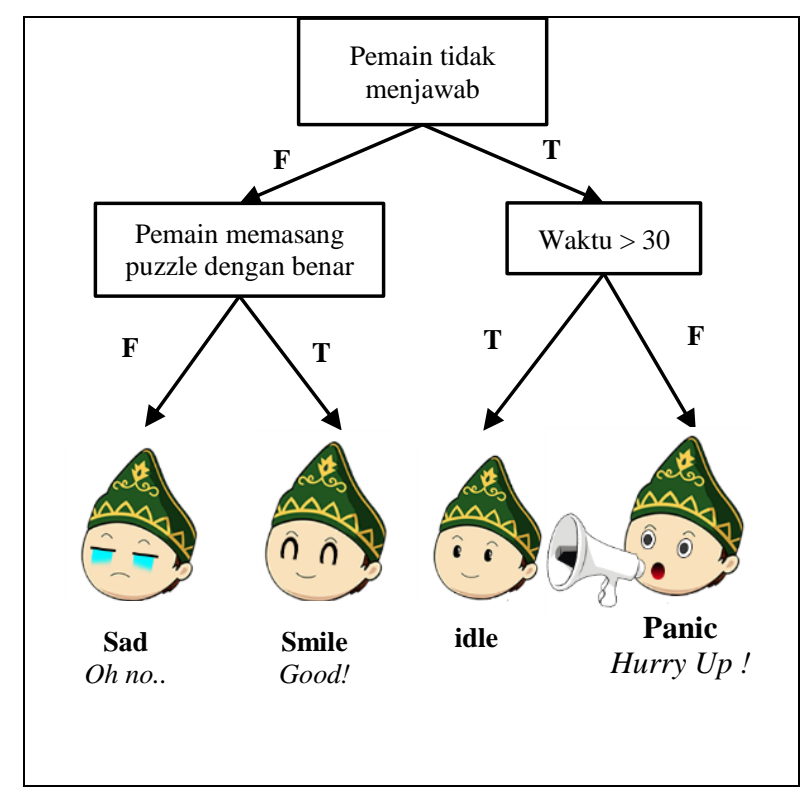

Gambar 6. Emoticon dari agen cerdas 
Dapat dilihat pada gambar 6 di atas, karakter dapat memberikan ekspresi sedih, bahagia, atau panik ketika waktu habis. Logika pohon keputusan akan membuat pemberitahuan ini tampak sesuai dari tindakan yang dilakukan pemain. Karakter lucu juga dapat berbicara untuk memberikan peringatan seperti guru pendamping bermain. Karakter juga bisa bahagia ketika pemain menang di babak ini (lihat gambar $7)$.

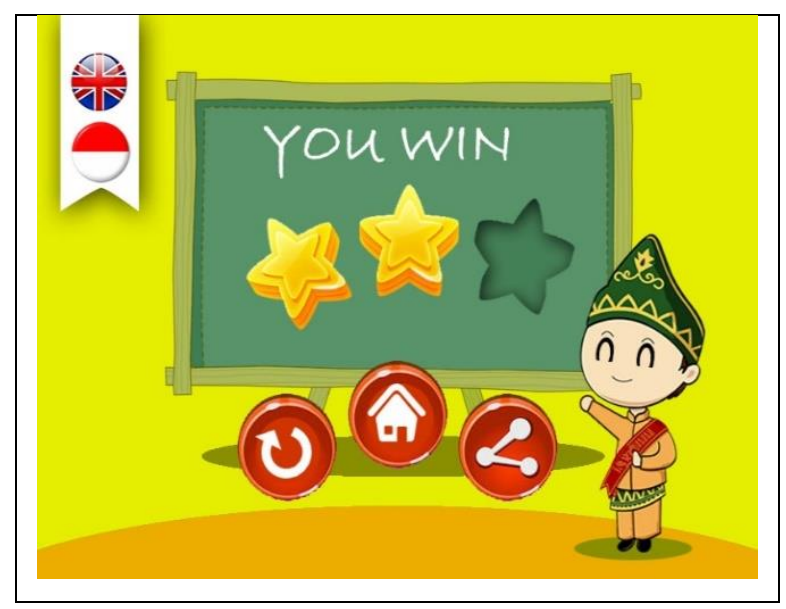

Gambar 7. Karakter Senang Ketika Pemain

\section{Menang}

Semua emoticon ini dibuat dengan tujuan membuat antarmuka game lebih interaktif dengan pemain anak. Sehingga anak-anak yang memainkan edugame ini merasa ditemani guru dengan kehadiran agen cerdas.

Pengujian beta adalah pengujian aplikasi langsung di lingkungan yang tidak dapat dikontrol oleh pengembang [15,17]. Uji coba dilakukan dalam bentuk kuesioner sederhana yang diisi oleh guru dan siswa SD Muhammadiyah 1. Dalam penelitian ini, uji coba dilakukan pada 10 guru dan 40 siswa, yang disajikan 5 pertanyaan yang mengacu pada gameplay dan peran agen permainan. Pertanyaan kuesioner dibuat sesederhana mungkin sehingga siswa juga dapat mengisinya.

Tabel 1. Hasil Pengujian Beta

\begin{tabular}{lcccc}
\hline Pertanyaan & \multicolumn{3}{c}{ Jawaban Responden } & TOTAL \\
\hline & Bagus & cukup & kurang & \\
\hline $\begin{array}{l}\text { Bagaimana desain } \\
\text { karakter? }\end{array}$ & 7 & 3 & 0 & 10 \\
$\begin{array}{l}\text { Bagimana tampilan } \\
\text { dari game ini? }\end{array}$ & 7 & 2 & 1 & 10 \\
$\begin{array}{l}\text { Bagaimana konten } \\
\text { pembelajarannya? }\end{array}$ & 6 & 3 & 1 & 10 \\
$\begin{array}{l}\text { Bagaimana music dan } \\
\text { audionya? }\end{array}$ & 6 & 2 & 2 & 10 \\
$\begin{array}{l}\text { Bagaimana gamplay } \\
\text { dari game ini? }\end{array}$ & 8 & 1 & 1 & 10 \\
Total Jawaban & 34 & 11 & 5 & $\mathbf{5 0}$ \\
\hline
\end{tabular}

Dari hasil pengujian beta pada tabel 1, kita dapat menentukan bobot perhitungan jawaban "kurang" dengan bobot nilai 1, untuk jawaban "cukup" dengan bobot 2, dan jawaban "baik" dengan bobot 3. Kemudian kita dapat menghitung persentase rata-rata responden .

$\bar{x}=\frac{34 \times 3+11 \times 2+5 \times 1}{50 \times 3} \times 100=86 \%$

Berdasarkan perolehan persentase kuesioner adalah $86 \%$, maka edugame "Unda Anak Pintar" dapat diterima, karena nilai pengujian yang diperoleh di atas persentase minimum 50\% (di atas cukup), dan mendekati 100\% (Baik sekali).

\section{KESIMPULAN}

Hasil penelitian ini menyimpulkan bahwa, telah berhasil dibangun edugame "Unda Anak Pintar" media pembelajaran muatan lokal bahasa Banjar dalam bentuk permainan puzzle huruf. Pengembangan aplikasi dilakukan sesuai dengan tahap pengembangan multimedia, mulai dari konsep, penerapan algoritma hingga pengujian aplikasi. Hadirnya agen cerdas yang menerapkan pohon keputusan membuat membuat karakter 
lucu dalam permainan dapat berinteraksi dengan gaya bermain pemain. Inilah yang membuat edugame lebih interaktif untuk anak-anak.

\section{UCAPAN TERIMA KASIH}

Direktorat Riset dan Pengabdian Masyarakat Direktorat Jenderal Penguatan Riset dan Pengembangan Kementerian Riset dan Teknologi/ Badan Riset dan Inovasi Nasional sesuai dengan Kontrak Penelitian Tahun Anggaran 2020.

\section{DAFTAR PUSTAKA}

[1] Basari, A., Penguatan Kurikulum Muatan Lokal dalam Pembelajaran di Sekolah Dasar. In Seminar Nasional Ilmu Pendidikan UNS, Sebelas Maret University. Prosiding Ilmu Pendidikan, 1(1), 2014.

[2] Sunarto, E., Mukarto, F. X., Bismoko, J., \& Dewi, N. Trilingual Textualization to Deliver Indonesian Local Cultures to High School Students. LLT Journal: A Journal on Language and Language Teaching, 21(1), 82-93, 2018.

[3] Permana, D. (2010). Fasa Nomina dalam Bahasa Banjar Samarinda. Jurnal Eksis, 6(1), 1267-1266.

[4] Syahidi, A., Supianto, A., \& Tolle, H. Design and Implementation of Bekantan Educational decision tree (BEG) as a Banjar Language Learning Media, 2019.

[5] Effendi, R. Eksistensi Sastra Lisan Mahalabiu bagi Masyarakat Banjar Kalimantan Selatan. LITERA, 11(2). 2012.

[6] Hasanah, R., Hidayat, E. W., \& Kurniati, N. I. Implementasi Deteksi Warna Pada Game Finding Color Menggunakan Ekstraksi Fitur Warna dan Fuzzy Decision Tree. Jurnal Teknik Informatika dan Sistem Informasi, 6(1), 2020.

[7] Mandziuk, J. Knowledge-free and learningbased methods in intelligent decision tree playing (Vol. 276). Heidelberg: Springer. 2010.

[8] Gerber, A., \& Götz, U. (Eds.). Architectonics of decision tree Spaces: The Spatial Logic of the Virtual and Its Meaning for the Real (Vol. 50). transcript Verlag, 2020.

[9] Rabin, S. Decision tree AI Pro 360: Guide to Architecture. CRC Press, 2019.

[10] Padmasari, A. C., Nurindiyani, A. K., \& Anggraeni, I. Penerapan Model Decision Tree untuk Rancangan Game Multiplayer Berbasis
Jaringan (Uka-Uka Tresure Hunter). Edsence: Jurnal Pendidikan Multimedia, 1(1), 19-24, 2019.

[11] Hasanudin, M., Salim, T., \& Robby, A. N. Rancang Bangun Aplikasi Game Puzzle Berbasis Android Menggunakan Algoritma Decision Tree. Journal Cerita, 3(2), 171-180, 2017.

[12] Meliani, G. R., \& Suryadi, A. Game Artificial Intelegent: RAM City Tower Dengan Algoritma A. Jurnal Petik, 3(2), 31-38, 2017.

[13] Savov, S. A., Antonova, R., \& Spassov, K. Multimedia applications in education. In Smart Technologies and Innovation for a Sustainable Future (pp. 263-271). Springer, Cham, 2019.

[14] Mulyana, I., Kom, M., Putra, A. P., Kom, M., Suriansyah, M. I., \& Kom, M. Buku Ajar Desain Grafis dan Multimedia (Vol. 1). Flash, 2019.

[15] Wibawanto, W., \& Ds, S. S. M. Desain dan Pemrograman Multimedia Pembelajaran Interaktif. Cerdas Ulet Kreatif Publisher, 2017.

[16] Jarzabek, S., Poniszewska-Marańda, A., \& Madeyski, L. (Eds.). Integrating Research and Practice in Software Engineering. Springer, 2020.

[17] Binanto, I. Multimedia digital-dasar teori dan pengembangannya. Penerbit Andi, 2010. 